VISUAL EXPERIMENT

\title{
Tail suspension test to evaluate the antidepressant activity of experimental drugs
}

\author{
Muhammad Aslam \\ Department of Pharmacology, Faculty of Pharmacy, Ziauddin University, Karachi 75600, Pakistan. \\ Correspondence at Pharmacologist1@yahoo.com; cell: +92-3452220192
}

First Published: 14 March, 2016

DOI: $10.3329 /$ bjp.v11i2.26517

\section{ABSTRACT}

Tail suspension test (TST) is a common behavioral paradigm used to evaluate the antidepressant activity of experimental drugs. Like the forced swimming test, in this test the animals are set in an inescapable yet modestly distressing circumstance. In the tail suspension test, the extent of immobility is thought to be associated with the depressive-like condition of the animal and is significantly diminished by antidepressant drugs.

\section{INTRODUCTION}

Tail suspension test is a common behavioral paradigm used to evaluate the antidepressant activity of experimental drugs. In this test the mice are suspended by their tails. Every mouse remains suspended for 6 mins. The behavior of the mouse to escape this aversive situation is recorded during this time. The tail suspension test was designed as an alternate choice for the forced swimming test, nevertheless the doctrine of both models remains same. Mice, suspended by their tails, intrinsically endeavor to get away from this aversive circumstance. However, as a result of the fizzled endeavor to get away, the mice experience despair and become immobile. The extent of immobility is thought to be associated with the depressive-like condition of the mice and is significantly diminished by antidepressant treatments (Aslam and Sultana, 2015; Cryan et al., 2005).

\section{MATERIALS AND EQUIPMENT}

Suspension bar:

In tail suspension test the mice are suspended by their tails. The experiment is conducted on a suspension bar or table. The height of the bar or table should be kept at $50 \mathrm{~cm}$ over the floor.

Tape:

Tape ought to hold fast safely to both the tail of the mouse and the suspension bar, and be sufficiently solid to bear the weight of the animal under experiment. The fragments, $17 \mathrm{~cm}$ each, of tape were cut and an imprint $2 \mathrm{~cm}$, on each fragment, was placed from one end. This $2 \mathrm{~cm}$ bit was utilized for appending the tape to the tail, whereas the remaining $15 \mathrm{~cm}$ was utilized for suspending the mouse on the bar.

Measuring tape:

Measuring tape was used to measure the fragments $(17 \mathrm{~cm}$ each) of the tape.

Cutter:

A cutter was used to cut fragments $(17 \mathrm{~cm}$ each) of the tape. 
Marker:

A marker was used to put an imprint $2 \mathrm{~cm}$, on each fragment from one end.

Timer:

Timer device was used to note the time of the test.

Video recording device:

Smartphone, Apple iPhone 5, was used to record the video clips.

\section{VIDEO CLIPS}

Pre-experiment: $\quad 53 \mathrm{sec}$

Experiment: $\quad 7 \mathrm{~min} 31 \mathrm{sec}$

\section{METHOD}

Procedure:

- Make the camera ready to record the video and place it in the right position. It is advised to place the camera as close as possible so that the high resolution video can be recorded.

- Bring the mice into the experiment room and leave them there for 1 hour for acclimation.

- Cut the fragments of the tape and mark them.

- Place the tape to the mouse's tail. Utilize the marked end of the tape and ensure the tape properly adheres to the tail. The tape ought to be connected to the ending part of the tail with 2-3 mm of the tail staying outside of the tape.

- When the tape has been appended to the mouse tail, affix the middle part of the tape to the suspension bar.

- Start the video recording.

- Start the timer already set at $6 \mathrm{~min}$. (360 Sec.).

- Once the experiment time (6 min) has elapsed, the mouse should be returned to the home cage and the tape should be removed from the tail by tenderly pulling it off. Try not to tear the tape from the tail because doing as such may cause pain to the animal.

\section{Scoring/Analysis:}

- Mostly, the tail suspension test is from beginning to end six min long. Dissimilar to another broadly utilized antidepressant technique, the forced swimming test, the entire session is scored. This is because of the fact that animals show immobility earlier in the TST.

- In our research centre, we transfer the video documents straightforwardly from the video recording device to a computer where the scoring is carried out.

- The scored parameter is the time that every animal spends as mobile.

- The most essential part of the TST behavioral investigation is the uniform recognition of movements that are scored as true mobility. The animals, particularly toward the start of the session, clearly show escaping behaviors. These incorporate attempting to arrive at the suspension bar, powerful shakes of the body, and movement of the appendages similar to running. These movements obviously constitute mobility. After a while these behaviors die down and get to be subtle. In our research facility little movements that are bound to forelimbs without the inclusion of the hind limbs are not considered mobility. Moreover, pendulum like swinging of animal body because of the momentum picked up amid the earlier mobility sessions are not considered mobility.

\section{DISCUSSION}

The designing of the tail suspension was impacted by the earlier designed forced swimming test (Steru et al., 1985; Porsolt et al., 1977; Porsolt et al., 1978). Like the forced swimming test, in this test the animals are set in an unpreventable yet modestly distressing circumstance. Absence of escaping behavior is regarded 
as immobility. Tail suspension test, like the forced swimming test, is a test best approved for the assessment of antidepressant-like effects of medications, additionally used to assess the impacts of ecological, neurobiological, and hereditary controls (Crowley et al., 2005; Lad et al., 2007). As opposed to the forced swimming test, in the tail suspension test there is no danger of hypothermia because of submersion in water (Thierry et al., 1986). The experimenters ought to remember that while the forced swimming test and tail suspension test are comparable at first sight, there are different critical contrasts in their affectability and execution and the consequences of one test may not as a matter of course be reproduced in the other. Despite the fact that the most of antidepressant medications take a number of weeks to show clinically critical impacts in patients, antidepressants can exert their effects in the tail suspension test and forced swimming test both subsequent to chronic and acute treatments (Cryan et al., 2005).

\section{REFERENCES}

Aslam M, Sultana N. Vitis vinifera juice ameliorates depression-like behavior in mice by modulating biogenic amine neurotransmitters. Bangladesh J Pharmacol. 2015; 10: 753-58.

Crowley J, Blendy J, Lucki I. Strain-dependent antidepressant-like effects of citalopram in the mouse tail suspension test. Psychopharmacology (Berl). 2005; 183: 257-64.

Cryan J, Mombereau C, Vassout A. The tail suspension test as a model for assessing antidepressant activity: Review of pharmacological and genetic studies in mice. Neurosci Biobehav Rev. 2005; 29: 571-625.

Lad H, Liu L, Payá-Cano J, Fernandes C, Schalkwyk L. Quantitative traits for the tail suspension test: Automation, optimization, and BXD RI mapping. Mamm Genome. 2007; 18: 482-91.

Porsolt R, Anton G, Blavet N, Jalfre M. Behavioral despair in rats: A new model sensitive to antidepressant treatments. Eur J Pharmacol. 1978; 47: 379-91.

Porsolt R, Bertin A, Jalfre M. Behavioral despair in mice: A primary screening test for antidepressants. Arch Int Pharmacodyn Ther. 1977; 229: 327-36.

Steru L, Chermat R, Thierry B, Simon P. The tail suspension test: A new method for screening antidepressants in mice. Psychopharmacology (Berl). 1985; 85: 367-70.

Thierry B, Steru L, Simon P, Porsolt R. The tail suspension test: Ethical considerations. Psychopharmacology (Berl). 1986; 90: 284-85. 


\section{Your feedback about this paper}

1. Number of times you have read this paper 0

2. Number of times you have seen the video clip 0

3. Which video you may need to see again, if any

4. Quality of paper
Excellent
Good
Moderate
Not good

5. Your comments

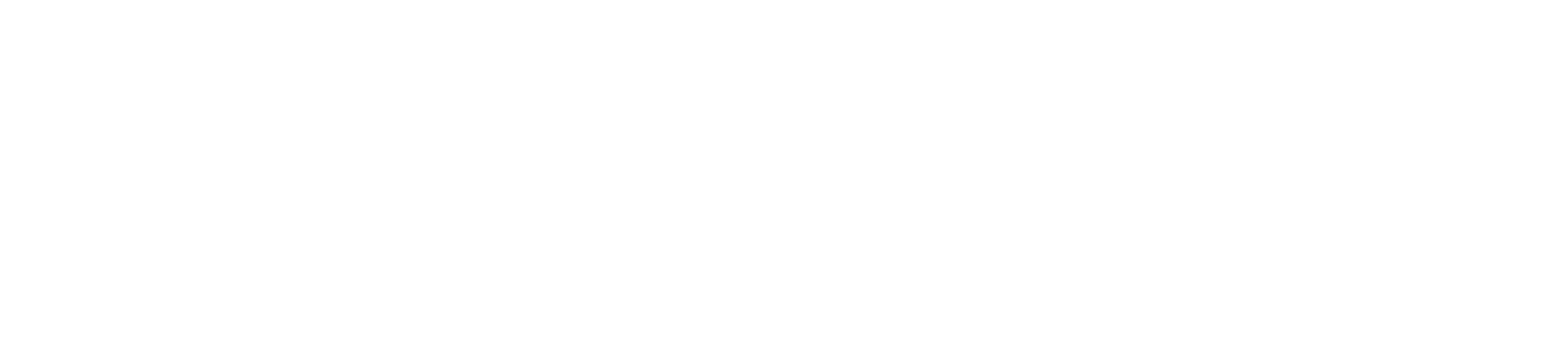

